\title{
NMR Measurement of Identical Polymer Samples by Round Robin Method II. Reliability of Spin-Lattice Relaxation Time and Nuclear Overhauser Enhancement Factor
}

\author{
Riichirô CHÛJÔ, Koichi HATAdA, ${ }^{*}$ Ryozo KITAMARU, ${ }^{* *}$ \\ Tatsuki KITAYAmA, ${ }^{*}$ Hisaya SATO, ${ }^{* * *}$ Yasuyuki TANAKA, ${ }^{* * *}$ \\ Fumitaka HORII,** and Yoshio TERAWAKI* \\ Department of Polymer Chemistry, Tokyo Institute of Technology, \\ Ookayama 2-chome, Meguro-ku, Tokyo 152, Japan \\ * Department of Chemistry, Faculty of Engineering Science, \\ Osaka University, Toyonaka, Osaka 560, Japan \\ **Institute for Chemical Research, Kyoto University, \\ Uji, Kyoto 611, Japan \\ *** Department of Material Systems Engineering, Faculty of Technology, \\ Tokyo University of Agriculture and Technology, \\ Koganei, Tokyo 184, Japan \\ (Received February 1, 1988)
}

\begin{abstract}
H}$ and ${ }^{13} \mathrm{C}$ NMR spin-lattice relaxation times $\left(\mathrm{T}_{1}\right)$ and ${ }^{13} \mathrm{C}$ nuclear Overhauser enhancement (NOE) of radically prepared poly(methyl methacrylate) $\left(\bar{M}_{n}=28500\right)$ in $\mathrm{CDCl}_{3}$ were measured on $27 \mathrm{NMR}$ spectrometers. Frequency range covered between 60 and $500 \mathrm{MHz}$ for ${ }^{1} \mathrm{H}$ NMR. Precision of ${ }^{1} \mathrm{H}-T_{1}$ 's of $\alpha-\mathrm{CH}_{3}$ and $\mathrm{CH}_{2}$ protons was less than $5 \%$. The ${ }^{1} \mathrm{H}-T_{1}$ 's of all sorts of protons increased linearly with increasing resonance frequency. The standard deviations for ${ }^{13} \mathrm{C}$ $T_{1}$ 's were larger than those for ${ }^{1} \mathrm{H}-T_{1}$ 's and exceeded $10 \%$ in some cases. The $T_{1}$ 's of all carbons except for the carbonyl carbon increased with frequency. The contribution of chemical shift anisotropy to the relaxation of the carbonyl carbon became significant above $25 \mathrm{MHz}$. The protons and carbons in the sequence rich in meso dyad showed longer $T_{1}$ 's than those in the corresponding sequence rich in racemo dyad. The precision of NOE was as good as that of ${ }^{13} \mathrm{C}-T_{1}$. The NOE's decreased as the observing frequency increased and particularly the NOE for the carbonyl carbon became almost unity at 100 and $125 \mathrm{MHz}$.

KEY WORDS ${ }^{1} \mathrm{H}$ NMR $/{ }^{13} \mathrm{C}$ NMR / Poly(methyl methacrylate) / Round Robin Method / Spin-Lattice Relaxation Time / Nuclear Overhauser Enhancement / Signal Intensity / Frequency Dependence / Precision / Accuracy /
\end{abstract}

Nuclear magnetic relaxation parameters give important information on molecular motion and have become more and more familiar to and inevitable for many NMR users after the Fourier transform (FT) method was introduced to NMR technology. The relaxation parameters are also of essential importance in adjusting data acquisition conditions in FT NMR measurement to obtain quantitative data. Research group on NMR, Society of Polymer Science, Japan (SPSJ), collected ${ }^{1} \mathrm{H}$ and ${ }^{13} \mathrm{C}$ NMR spectra of two identical samples, poly(methyl methacrylate) and solanesol, from a number of NMR spectrometers. The results of assessment on the reliability of chemical shift and signal intensity were reported previously. ${ }^{1}$ Insufficient agreement in the ${ }^{13} \mathrm{C}$ signal intensity urged us to assess the 


\section{R. CHû̀ô et al.}

reliability of spin-lattice relaxation time $\left(T_{1}\right)$ and nuclear Overhauser enhancement (NOE) factor which are required for proper setting of conditions of measurements. It is also important to know whether or not the precision of determination of these parameters allows us to treat them as one of the characteristics of a polymer.

In polymer science power spectrum or frequency dependence is very important to elucidate molecular motion. The measurement of frequency dependence is, therefore, quite familiar in dielectric and/or mechanical relaxation studies. Meanwhile, a similar measurement is impossible in NMR study with one NMR instrument. Cooperation of many researchers with different instruments makes it possible to make measurements.

In this series of cooperative project several non-members as well as SPSJ members*1 were invited to participate. The data were collected from spectrometers whose observing frequencies ranged from 60 to $500 \mathrm{MHz}$ for ${ }^{1} \mathrm{H}$ NMR and from 15 to $125 \mathrm{MHz}$ for ${ }^{13} \mathrm{C} \mathrm{NMR}$. As a result, frequency dependences of $T_{1}$ and NOE were obtained for a very wide range of frequencies. This paper reports the results of the reliability and consistency of $T_{1}$ and NOE values for the PMMA sample. A preliminary analysis of the data has been made $^{2}$ and the details will be published in the near future.

\section{EXPERIMENTAL}

Poly(methyl methacrylate)

Preparation and characterization of the
PMMA are described in the previous paper. ${ }^{1}$ Mean values for triad tacticities determined by ${ }^{1} \mathrm{H}$ NMR spectroscopy and their standard deviations, $\sigma$, are

$$
\begin{array}{ll}
m m=4.0 \%, & \sigma=0.9, \\
m r=34.7 \%, & \sigma=1.0, \\
r r=61.3 \%, & \sigma=1.5 .
\end{array}
$$

The molecular weights are;

$$
\begin{gathered}
\bar{M}_{n}(\mathrm{GPC})=27400, \\
\bar{M}_{n}(\mathrm{VPO})=28500, \\
\bar{M}_{w}(\mathrm{GPC})=58000 .
\end{gathered}
$$

\section{Measurement}

A $10 \mathrm{w} / \mathrm{v} \% \mathrm{CDCl}_{3}$ solution of the PMMA was degassed and sealed under nitrogen into $5 \mathrm{~mm}$ o.d. (for ${ }^{1} \mathrm{H}$ NMR measurements) and $10 \mathrm{~mm}$ o.d. (for ${ }^{13} \mathrm{C}$ NMR measurements) NMR sample tubes. The test samples were distributed to collaborating test sites. One particular sample (sample No. 1) was circulated to several test sites to obtain data on exactly the same sample from different instruments. In addition, some collaborators made measurements on sample solutions prepared by themselves from the distributed solid PMMA to assess any effects of sample preparation conditions on the data.

A requested method of $T_{1}$ determination was the inversion-recovery method with a pulse sequence of $\left(180^{\circ}-\tau-90^{\circ}-t\right)_{n}$. The time delays, $\tau$ and $t$, executed had the following ranges:

*1 S. Amiya (Kuraray Central Research Laboratory), T. Asakura (Tokyo University of Agriculture and Technology), K. Chikaishi (Sumitomo Chemical Co. Ltd.), Y. Goto (University of Tokyo), K. Hikichi (Hokkaido University), Y. Hirakida (Showa Denko K.K.), S. Hosoda (Sumitomo Chemical Co., Ltd.), M. Imanari (JEOL Ltd.), S. Itoh (Kyoto University), M. Kamachi (Osaka University), T. Kawamura (University of Tokyo), S. Kohjiya (Kyoto Institute of Technology), K. Lee (Osaka University), I. Nagoya (Asahi Chemical Industry Co.), Y. Oka (Mitsui Toatsu Chemicals, Inc.), T. Okada (Tosoh Corporation), M. Okumura (Toa Nenryo Kogyo Kabushikigaisha), T. Saito (Nippon Oil Company, Ltd.), T. Sei (Daicel Chemical Industries, Ltd.), T. Seimiya (Idemitsu Kosan Co.), T. Shiibashi (Japan Synthetic Rubber Co.), T. Shimamura (Nitto Technical Information Center Co., Ltd.), M. Shimoda (Nippon Zeon Co., Ltd.), Y. Takai (Osaka University), T. Usami (Mitsubishi Petrochemical Co.), K. Ute (Osaka University), T. Yonemitsu (Kyushu Sangyo University). 


\begin{tabular}{lcc}
\hline & $\tau$ & $t$ \\
\hline${ }^{1} \mathrm{H}-T_{1}$ & $0.001-10 \mathrm{~s}$ & $4-20 \mathrm{~s}$ \\
${ }^{13} \mathrm{C}-T_{1}$ of $\alpha-\mathrm{CH}_{3}$ & $0.005-10 \mathrm{~s}$ & $1-20 \mathrm{~s}$ \\
$\quad$ and $\mathrm{CH}_{2}$ \\
$\begin{array}{l}{ }^{13} \mathrm{C}-T_{1} \text { of other } \\
\text { carbons }\end{array}$ & $0.010-15 \mathrm{~s}$ & $10-20 \mathrm{~s}$ \\
\hline
\end{tabular}

NOE was determined from the intensity ratio of each carbon signal in the completely decoupled spectrum and gated decoupled spectrum without NOE. The executed conditions for the ${ }^{13} \mathrm{C}$ NOE determination were as follows:

pulse repetition time, $\quad 20-25 \mathrm{~s}$

number of scans, $\quad 1000-2048$

\section{RESULTS AND DISCUSSION}

\section{${ }^{1}$ H Spin-Lattice Relaxation Times of PMMA}

${ }^{1} \mathrm{H}-T_{1}$ 's of the PMMA in $\mathrm{CDCl}_{3}$ were determined from the spectra measured on 27 spectrometers, whose resonance frequencies ranged from 60 to $500 \mathrm{MHz}$. Individual $T_{1}$ data for $\alpha-\mathrm{CH}_{3}$ protons in $\mathrm{rr}$ and mr triads, $\mathrm{CH}_{2}$ and $\mathrm{OCH}_{3}$ protons are listed in Table I in

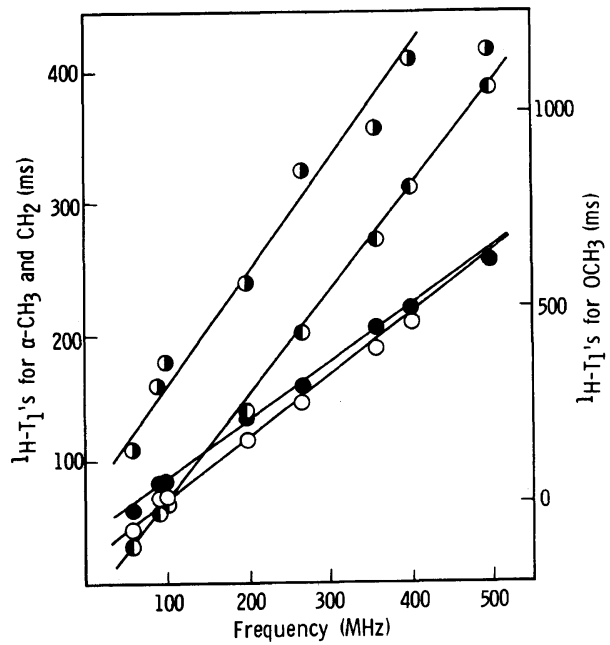

Figure 1. Frequency dependence of ${ }^{1} \mathrm{H}-T_{1}$ 's of PMMA measured in $\mathrm{CDCl}_{3}$ at $55^{\circ} \mathrm{C}: \mathrm{O}, \alpha-\mathrm{CH}_{3}(r r) ; \bigcirc, \alpha-\mathrm{CH}_{3}$ $(m r) ; \boldsymbol{\top}, \mathrm{CH}_{2}(r r r) ; \mathrm{O}, \mathrm{OCH}_{3}$. the order of increasing resonance frequency. ${ }^{1} \mathrm{H}-T_{1}$ values increased with increasing magnetic field strength. The values obtained at any fixed frequency scatter only slightly with few exceptions. Table II summarizes the mean values and standard deviations of ${ }^{1} \mathrm{H}-T_{1}$ 's determined at each resonance frequency. The precisions for ${ }^{1} \mathrm{H}-T_{1}$ 's of $\alpha-\mathrm{CH}_{3}$ and $\mathrm{CH}_{2}$ protons are as good as $5 \%$. These $T_{1}$ values can be regarded as characteristic data for the polymer as long as obtained under the specified conditions. ${ }^{1} \mathrm{H}-T_{1}$ data for $\mathrm{OCH}_{3}$ protons showed a little larger standard deviations, partly due to the long $T_{1}$ values. $\alpha$-Methyl protons in $\mathrm{mr}$ triad showed longer ${ }^{1} \mathrm{H}-T_{1}$ than those in $\mathrm{rr}$ triad at each resonance frequency. The results clearly confirm similar observations by several investigators. ${ }^{3-9}$ In Figure 1, the mean values of ${ }^{1} \mathrm{H}-T_{1}$ 's are plotted against the resonance frequency for the respective protons. As is clearly seen in this figure, the $T_{1}$ values linearly increase with increasing resonance frequency for each proton but the slope of the straight line is considerably small for the $\alpha-\mathrm{CH}_{3}$ protons compared to the others. As a result, the $\alpha-\mathrm{CH}_{3}$ protons exhibit shorter ${ }^{1} \mathrm{H}-T_{1}$ 's than $\mathrm{CH}_{2}$ protons at frequencies high-

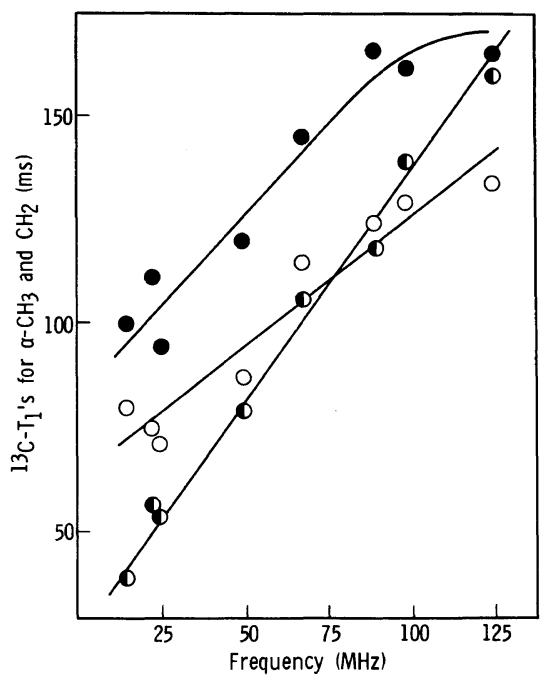

Figure 2. Frequency dependence of ${ }^{13} \mathrm{C}-T_{1}$ 's for $\alpha-\mathrm{CH}_{3}$ and $\mathrm{CH}_{2}$ carbons of PMMA measured in $\mathrm{CDCl}_{3}$ at $55^{\circ} \mathrm{C}: \mathrm{O}, \alpha-\mathrm{CH}_{3}(r r) ; \bigcirc, \alpha-\mathrm{CH}_{3}(m r) ;$ ○, $\mathrm{CH}_{2}$. 
Table I. Measurements of ${ }^{1} \mathrm{H}-T_{1}$ (ms) for PMMA in $\mathrm{CDCl}_{3}$ at $55^{\circ} \mathrm{C}$ by various spectrometers at different frequencies

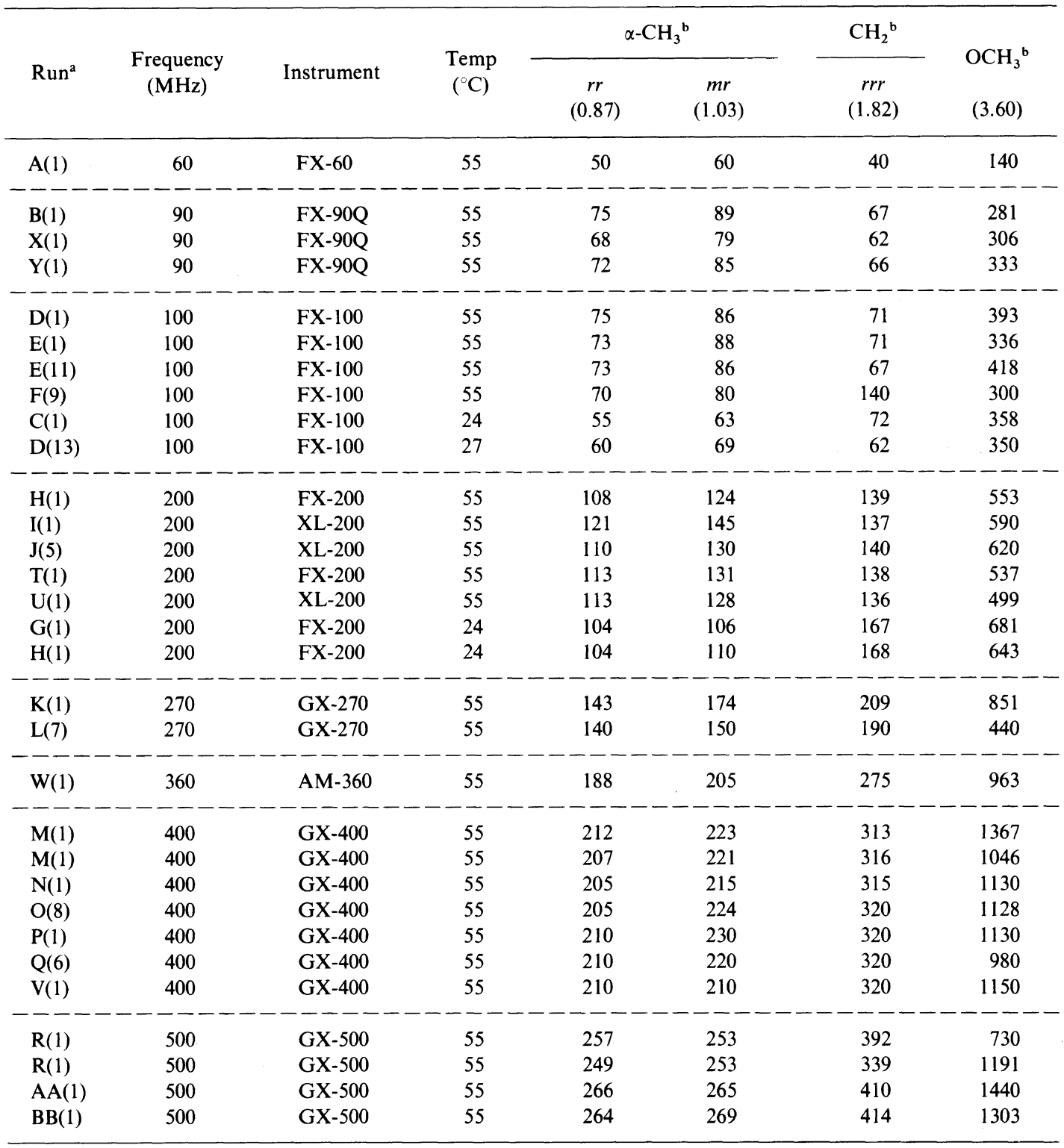

a Figures in parentheses denote sample numbers.

b Figures in parentheses denote chemical shifts measured at $55^{\circ} \mathrm{C}$ in $\mathrm{CDCl}_{3}$.

er than $100 \mathrm{MHz}$, although the former has more nearest-neighbor protons than $\mathrm{CH}_{2}$ protons. However, it seems very complicated to analyze these frequency dependencies in terms of simple models for the proton magnetic relaxation, because the previous ${ }^{1} \mathrm{H}$ NMR studies $^{3,5}$ revealed that cross relaxation significantly occurs among these protons.

Sample No. 1 was circulated to a number of test sites. No meaningful differences were ob- 
Table II. ${ }^{1} \mathrm{H}-T_{1}$ 's (ms) of PMMA measured in $\mathrm{CDCl}_{3}$ at $55^{\circ} \mathrm{C}$ at different frequencies

Freq.
$(\mathrm{MHz})$$n^{\mathrm{a}} \frac{{ }^{\alpha-\mathrm{CH}_{3}{ }^{\mathrm{b}}}}{r r \quad m r} \frac{\mathrm{CH}_{2}{ }^{\mathrm{b}}}{r r r} \mathrm{OCH}_{3}{ }^{\mathrm{b}}$

\begin{tabular}{cccccc}
\hline 60 & 1 & $50(-)$ & $60(-)$ & $40(-)$ & $140(-)$ \\
90 & 3 & $72(4.0)$ & $84(4.9)$ & $65(3.3)$ & $307(6.9)$ \\
100 & 3 & $74(1.3)^{\mathrm{d}}$ & $87(1.1)^{\mathrm{d}}$ & $70(2.7)^{\mathrm{d}}$ & $382(9.0)^{\mathrm{d}}$ \\
$100^{\mathrm{c}}$ & 2 & $58(4.3)$ & $66(4.5)$ & $67(7.5)$ & $354(1.1)$ \\
200 & 5 & $113(3.9)$ & $132(5.4)$ & $138(1.0)$ & $560(7.5)$ \\
$200^{\mathrm{c}}$ & 2 & $104(0)$ & $108(1.8)$ & $168(0.3)$ & $662(0.3)$ \\
270 & 2 & $142(0.1)$ & $162(7.4)$ & $200(4.7)$ & $851(-)^{\mathrm{e}}$ \\
360 & 1 & $188(-)$ & $205(-)$ & $275(-)$ & $963(-)$ \\
400 & 7 & $208(1.3)$ & $220(2.7)$ & $318(0.9)$ & $1133(9.8)$ \\
500 & 4 & $259(2.3)$ & $260(2.5)$ & $389(6.9)$ & $1166(20.5)$
\end{tabular}

a Number of determinations.

b Figures in parentheses represent precision ( $\%)$.

c Measurements were done at room temperature (24 and $27^{\circ} \mathrm{C}$ ).

d The data $\mathrm{F}(9)$ were deleted.

e $T_{1}$ value of $\mathrm{L}(7)$ for $\mathrm{OCH}_{3}$ was deleted.

Table III. Measurements of ${ }^{1} \mathrm{H}-T_{1}$ (ms) at $55^{\circ} \mathrm{C}$ on the solution of PMMA in $\mathrm{CDCl}_{3}$ prepared by each investigator

\begin{tabular}{|c|c|c|c|c|c|}
\hline & \multirow{2}{*}{$\begin{array}{l}\text { Frequency } \\
(\mathrm{MHz})\end{array}$} & \multicolumn{2}{|c|}{$\alpha-\mathrm{CH}_{3}$} & \multirow{2}{*}{$\frac{\mathrm{CH}_{2}}{r r r}$} & \multirow{2}{*}{$\mathrm{OCH}_{3}$} \\
\hline & & $r r$ & $m r$ & & \\
\hline D & 100 & 74 & 87 & 70 & 398 \\
\hline $\mathrm{E}$ & 100 & 76 & 91 & 72 & 286 \\
\hline $\mathrm{U}$ & 200 & 111 & 125 & 136 & 443 \\
\hline $\mathrm{H}$ & 200 & 109 & 129 & 128 & 553 \\
\hline $\mathbf{M}$ & 400 & 204 & 218 & 321 & 1007 \\
\hline
\end{tabular}

served in ${ }^{1} \mathrm{H}-T_{1}$ values for different samples (Table I).

The data were also collected for sample solutions prepared at several test sites by each collaborator. The results obtained are shown in Table III and are in good agreement with the data shown in Table I. Therefore, as long as the preparation conditions of sample solution are specified, the $T_{1}$ data should not be altered substantially.

Possibly higher static magnetic fields are preferable for obtaining spectra with higher signal-to-noise $(\mathrm{S} / \mathrm{N})$ ratios. However, Figure 2 suggests that the increase in ${ }^{1} \mathrm{H}-T_{1}$ at higher magnetic field strength requires setting a longer time as a repetition time between single rf pulses for the measurements. This would result in a decrease in practical $\mathrm{S} / \mathrm{N}$ ratio obtainable within a limited period of time.

\section{${ }^{13}$ C Spin-Lattice Relaxation Times of PMMA}

${ }^{13} \mathrm{C}-T_{1}$ 's for the PMMA in $\mathrm{CDCl}_{3}$ were measured at $55^{\circ} \mathrm{C}$ on 27 instruments, whose resonance frequency ranged from 15.0 to $125 \mathrm{MHz}$. The individual data are collected in Table IV. In Table $\mathrm{V}$ are summarized mean values and standard deviations at each resonance frequency. The deviations for ${ }^{13} \mathrm{C}-T_{1}$ 's are larger than those for ${ }^{1} \mathrm{H}-T_{1}$ 's and exceed $10 \%$ in some cases. Scattering of the data does not seem to be noticeably different with regard to types of carbon, though the deviation for $\mathrm{OCH}_{3}$ is slightly larger than those of others similarly to the case of ${ }^{1} \mathrm{H}-T_{1}$ for $\mathrm{OCH}_{3} \cdot{ }^{13} \mathrm{C}$ $T_{1}$ values of $\alpha$-methyl, quaternary and carbonyl carbons were determined for split signals due to tacticity. Carbons in the sequence rich in meso dyad generally showed larger ${ }^{13} \mathrm{C}$ -

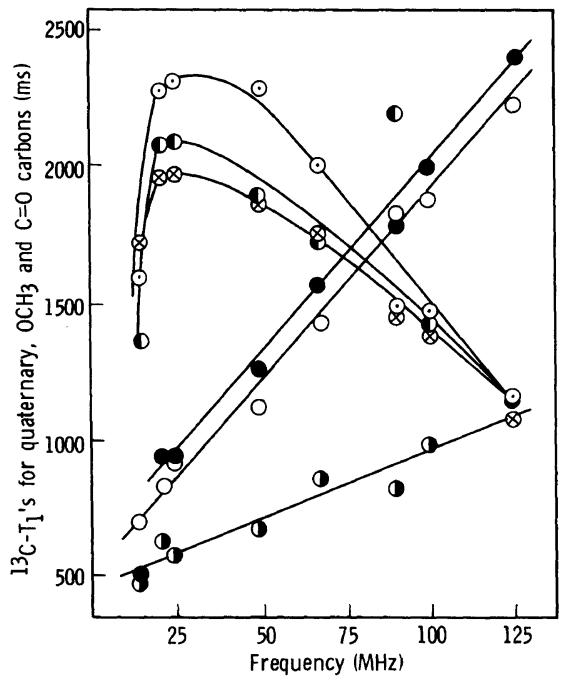

Figure 3. Frequency dependence of ${ }^{13} \mathrm{C}-T_{1}$ 's for quaternary, $\mathrm{OCH}_{3}$ and carbonyl carbons of PMMA measured in $\mathrm{CDCl}_{3}$ at $55^{\circ} \mathrm{C}: \mathrm{O}, \mathrm{OCH}_{3} ; \mathrm{O}$, quaternary $(\mathrm{rr})$; $\bigcirc$, quaternary $(\mathrm{mr}) ; \boldsymbol{\bigcirc}$, carbonyl $(\mathrm{rrm})$; $\odot$, carbonyl $(m m r r+r m r r) ; \otimes$, carbonyl $(r r r)$. 
R. CHÛJô et al.

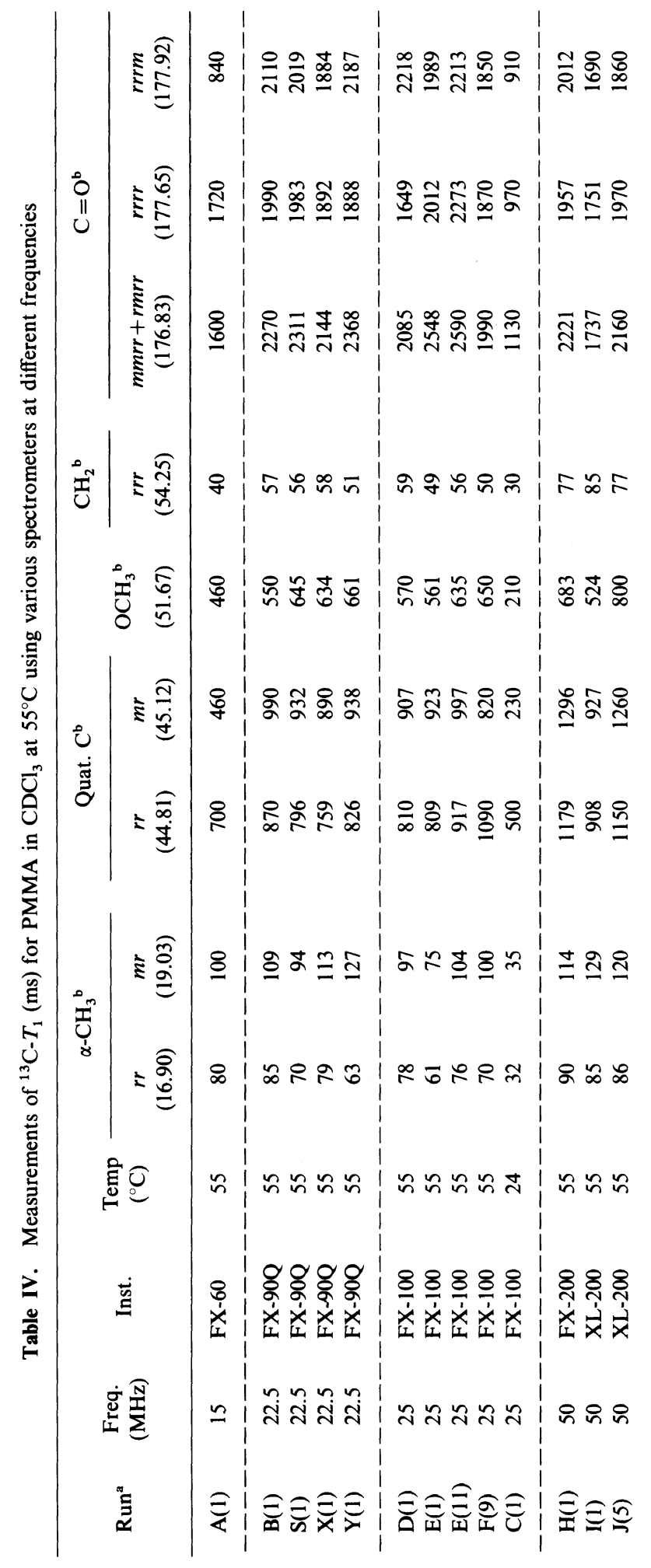


NMR Relaxation Parameters of PMMA

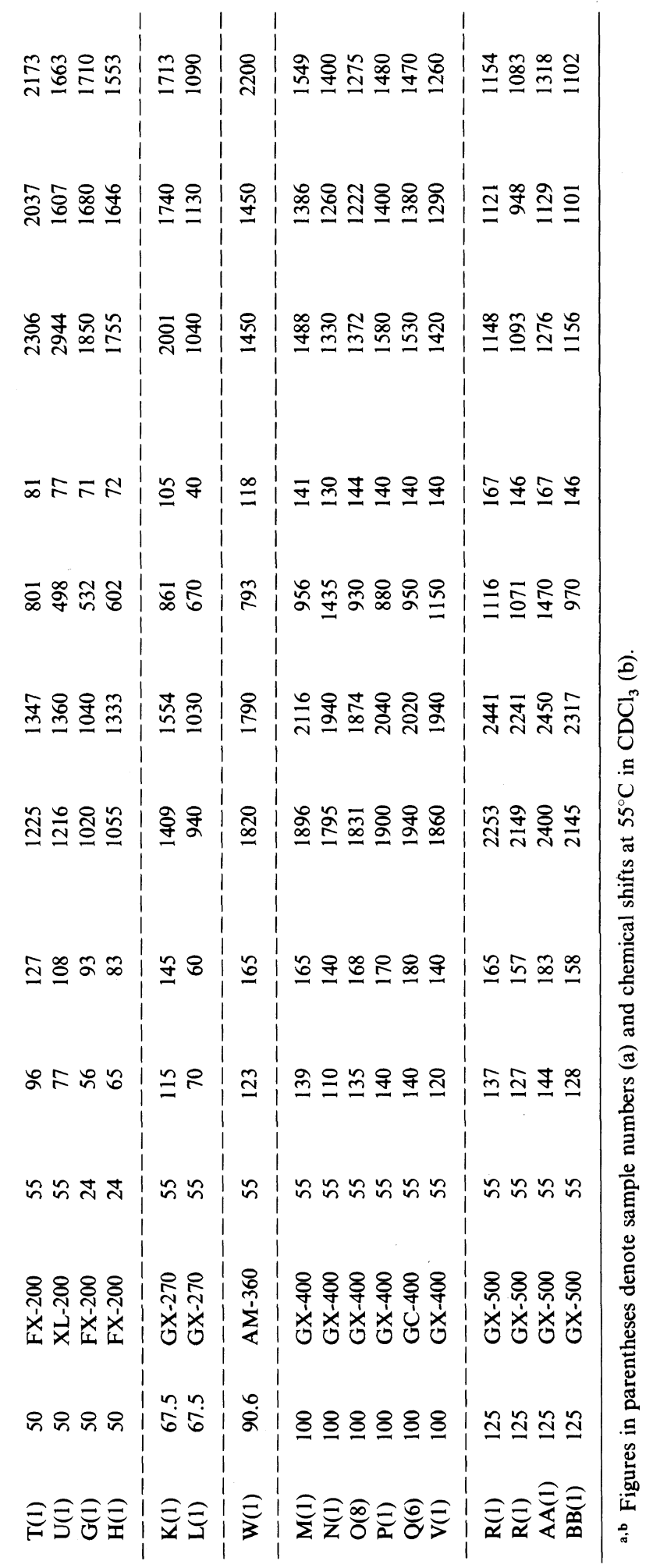


Table V. ${ }^{13} \mathrm{C}-T_{1}(\mathrm{~ms})$ of PMMA measured in $\mathrm{CDCl}_{3}$ at $55^{\circ} \mathrm{C}$ at different frequencies

\begin{tabular}{|c|c|c|c|c|c|c|c|c|c|c|}
\hline \multirow{2}{*}{$\begin{array}{l}\text { Frequency } \\
\quad(\mathrm{MHz})\end{array}$} & \multirow{2}{*}{$n^{\mathrm{a}}$} & \multicolumn{2}{|c|}{$\alpha-\mathrm{CH}_{3}{ }^{\mathbf{b}}$} & \multicolumn{2}{|c|}{ Quat. Cb } & \multirow{2}{*}{$\mathrm{OCH}_{3}{ }^{\mathrm{b}}$} & \multirow{2}{*}{$\frac{\mathrm{CH}_{2}{ }^{\mathrm{b}}}{r r r}$} & \multicolumn{3}{|c|}{$\mathrm{C}=\mathrm{O}^{\mathrm{b}}$} \\
\hline & & $r r$ & $m r$ & $r r$ & $m r$ & & & $m m r r+r m r r$ & $r r r r$ & $\mathrm{rrrm}$ \\
\hline 15 & 1 & 80 & 100 & 700 & 460 & 460 & 40 & 1600 & 1720 & 840 \\
\hline 22.5 & 4 & $\begin{array}{c}74 \\
(11.4)\end{array}$ & $\begin{array}{c}111 \\
(10.6)\end{array}$ & $\begin{array}{c}813 \\
(5.0)\end{array}$ & $\begin{array}{c}938 \\
(3.8)\end{array}$ & $\begin{array}{c}623 \\
(6.9)\end{array}$ & $\begin{array}{r}56 \\
(4.8)\end{array}$ & $\begin{array}{c}2273 \\
(3.6)\end{array}$ & $\begin{array}{c}1938 \\
(2.5)\end{array}$ & $\begin{array}{l}2050 \\
(5.5)\end{array}$ \\
\hline 25 & 4 & $\begin{array}{c}71 \\
(9.3)\end{array}$ & $\begin{array}{c}94 \\
(12.0)\end{array}$ & $\begin{array}{c}907 \\
(12.6)\end{array}$ & $\begin{array}{c}912 \\
(6.9)\end{array}$ & $\begin{array}{c}604 \\
(6.5)\end{array}$ & $\begin{array}{r}54 \\
(7.7)\end{array}$ & $\begin{array}{c}2303 \\
(11.7)\end{array}$ & $\begin{array}{c}1951 \\
(11.6)\end{array}$ & $\begin{array}{l}2068 \\
(7.5)\end{array}$ \\
\hline 50 & 5 & $\begin{array}{c}87 \\
(7.2)\end{array}$ & $\begin{array}{c}120 \\
(6.6)\end{array}$ & $\begin{array}{c}1136 \\
(10.3)\end{array}$ & $\begin{array}{c}1238 \\
(12.9)\end{array}$ & $\begin{array}{c}661 \\
(19.7)\end{array}$ & $\begin{array}{r}79 \\
(4.1)\end{array}$ & $\begin{array}{c}2274 \\
(17.8)\end{array}$ & $\begin{array}{c}1864 \\
(8.6)\end{array}$ & $\begin{array}{l}1880 \\
(9.2)\end{array}$ \\
\hline $50^{\mathrm{c}}$ & 2 & $\begin{array}{c}61 \\
(7.4)\end{array}$ & $\begin{array}{c}88 \\
(5.7)\end{array}$ & $\begin{array}{c}1038 \\
(1.7)\end{array}$ & $\begin{array}{c}1242 \\
(16.3)\end{array}$ & $\begin{array}{c}567 \\
(6.2)\end{array}$ & $\begin{array}{c}72 \\
(0.7)\end{array}$ & $\begin{array}{c}1803 \\
(2.6)\end{array}$ & $\begin{array}{c}1663 \\
(1.0)\end{array}$ & $\begin{array}{l}1632 \\
(4.8)\end{array}$ \\
\hline $67.5^{d}$ & 1 & 115 & 145 & 1409 & 1554 & 861 & 105 & 2001 & 1740 & 1713 \\
\hline 90.6 & 1 & 123 & 165 & 1820 & 1790 & 793 & 118 & 1450 & 1450 & 2200 \\
\hline 100 & 6 & $\begin{array}{c}129 \\
(8.5)\end{array}$ & $\begin{array}{c}161 \\
(9.5)\end{array}$ & $\begin{array}{c}1870 \\
(2.6)\end{array}$ & $\begin{array}{c}1988 \\
(4.0)\end{array}$ & $\begin{array}{c}973 \\
(9.7)\end{array}$ & $\begin{array}{c}139 \\
(3.2)\end{array}$ & $\begin{array}{c}1453 \\
(6.0)\end{array}$ & $\begin{array}{c}1323 \\
(5.2)\end{array}$ & $\begin{array}{l}1406 \\
(7.6)\end{array}$ \\
\hline 125 & 4 & $\begin{array}{c}134 \\
(5.2)\end{array}$ & $\begin{array}{c}165 \\
(6.3)\end{array}$ & $\begin{array}{r}2237 \\
(4.6)\end{array}$ & $\begin{array}{c}2362 \\
(3.7)\end{array}$ & $\begin{array}{c}1157 \\
(16.3)\end{array}$ & $\begin{array}{c}156 \\
(6.7)\end{array}$ & $\begin{array}{c}1168 \\
(5.7)\end{array}$ & $\begin{array}{c}1075 \\
(6.9)\end{array}$ & $\begin{array}{l}1164 \\
(7.9)\end{array}$ \\
\hline
\end{tabular}

a Number of determinations.

b Figures in parentheses represent precision (\%).

c Measurement was made at room temperature $\left(24^{\circ} \mathrm{C}\right)$.

d The data L(7) were deleted.

$T_{1}$ 's than the corresponding carbons in the sequence rich in racemo dyad, as observed for ${ }^{1} \mathrm{H}-T_{1}$ of $\alpha-\mathrm{CH}_{3}$ protons. Similar results on the ${ }^{13} \mathrm{C}-T_{1}$ of PMMA have been reported by several investigators. ${ }^{5,10-15}$ Figures 2 and 3 illustrate resonance frequency dependences of the mean values of ${ }^{13} \mathrm{C}-T_{1} \cdot{ }^{13} \mathrm{C}-T_{1}$ 's for all carbons except for carbonyl carbon increase linearly with increasing resonance frequencies. The $\alpha$ $\mathrm{CH}_{3}$ carbon in $\mathrm{rr}$ triad shows longer $T_{1}$ than the $\mathrm{CH}_{2}$ carbon in rrr tetrad at the lower frequencies but shorter $T_{1}$ at the higher frequencies, and the inversion in the order of magnitudes of ${ }^{13} \mathrm{C}-\mathrm{T}_{1}$ for $\alpha-\mathrm{CH}_{3}$ and $\mathrm{CH}_{2}$ carbons occurs at the frequency between 67.5 and $90.6 \mathrm{MHz}$. Preliminary analyses have already shown that these frequency dependences of $\alpha-\mathrm{CH}_{3}, \mathrm{CH}_{2}$, and $\mathrm{OCH}_{3}$ carbons can be interpreted by molecular motional models in which the motion of the $\mathrm{C}-\mathrm{H}$ internuclear vector is described in terms of three independent superposed motions with different correlation times. ${ }^{2}$ The details of the explanation of difference in the frequency dependencies of the carbons will be published in this Journal.

${ }^{13} \mathrm{C}-T_{1}$ 's for the carbonyl carbon decrease with increasing resonance frequencies above $25 \mathrm{MHz}$. The relaxation induced by chemical shift anisotropy is possible for the carbons in $\pi$-bond. The relaxation by this mechanism becomes important at higher magnetic field, since the contribution of chemical shift anisotropy to the relaxation rate is proportional to the square of the static magnetic field strength if the molecular tumbling rate is much larger than the resonance frequency. ${ }^{16}$ The relaxation of the acetylenic carbons in 1,4-diphenylbutadiyne is a typical example of this case. ${ }^{17}$ The great decrease in ${ }^{13} \mathrm{C}-T_{1}$ of the carbonyl carbon in PMMA with increasing magnetic field indicates increasing contribution of the chemical shift anisotropy to the spin-lattice relaxation. To our knowledge, this is the first example of polymer system where the contribution of the chemical shift anisotropy to the relaxation was proved. Though the frequency dependency of ${ }^{13} \mathrm{C}$ relaxation was reported recently on poly(butyl methacrylate), the au- 
NMR Relaxation Parameters of PMMA

Table VI. Measurements of ${ }^{13} \mathrm{C}-T_{1}(\mathrm{~ms})$ at $55^{\circ} \mathrm{C}$ on solutions of PMMA in $\mathrm{CDCl}_{3}$ prepared by the investigators

\begin{tabular}{|c|c|c|c|c|c|c|c|c|c|c|c|}
\hline & \multirow{2}{*}{$\begin{array}{l}\text { Frequency } \\
\qquad(\mathrm{MHz})\end{array}$} & \multirow{2}{*}{ Instrument } & \multicolumn{2}{|c|}{$\alpha-\mathrm{CH}_{3}$} & \multicolumn{2}{|c|}{ Quat. C } & \multirow{2}{*}{$\mathrm{OCH}_{3}$} & \multirow{2}{*}{$\frac{\mathrm{CH}_{2}}{r r r}$} & \multicolumn{3}{|c|}{$\mathrm{C}=\mathrm{O}$} \\
\hline & & & $r r$ & $m r$ & $r r$ & $m r$ & & & $m m r r+r m r r$ & $r r r r$ & $\mathrm{rrrm}$ \\
\hline $\mathrm{E}$ & 25 & FX-100 & 64 & 84 & 1011 & 888 & 564 & 51 & 2844 & 2186 & 2797 \\
\hline $\mathrm{H}$ & 50 & FX-200 & 80 & 115 & 1780 & 1290 & 680 & 79 & 2240 & 1970 & 2030 \\
\hline $\mathrm{U}$ & 50 & XL-200 & 90 & 112 & 1161 & 1356 & 667 & 82 & 1979 & 2031 & 1953 \\
\hline
\end{tabular}

Table VII. Measurements of ${ }^{13} \mathrm{C}$ NOE for PMMA in $\mathrm{CDCl}_{3}$ at $55^{\circ} \mathrm{C}$ by various spectrometers at different frequencies

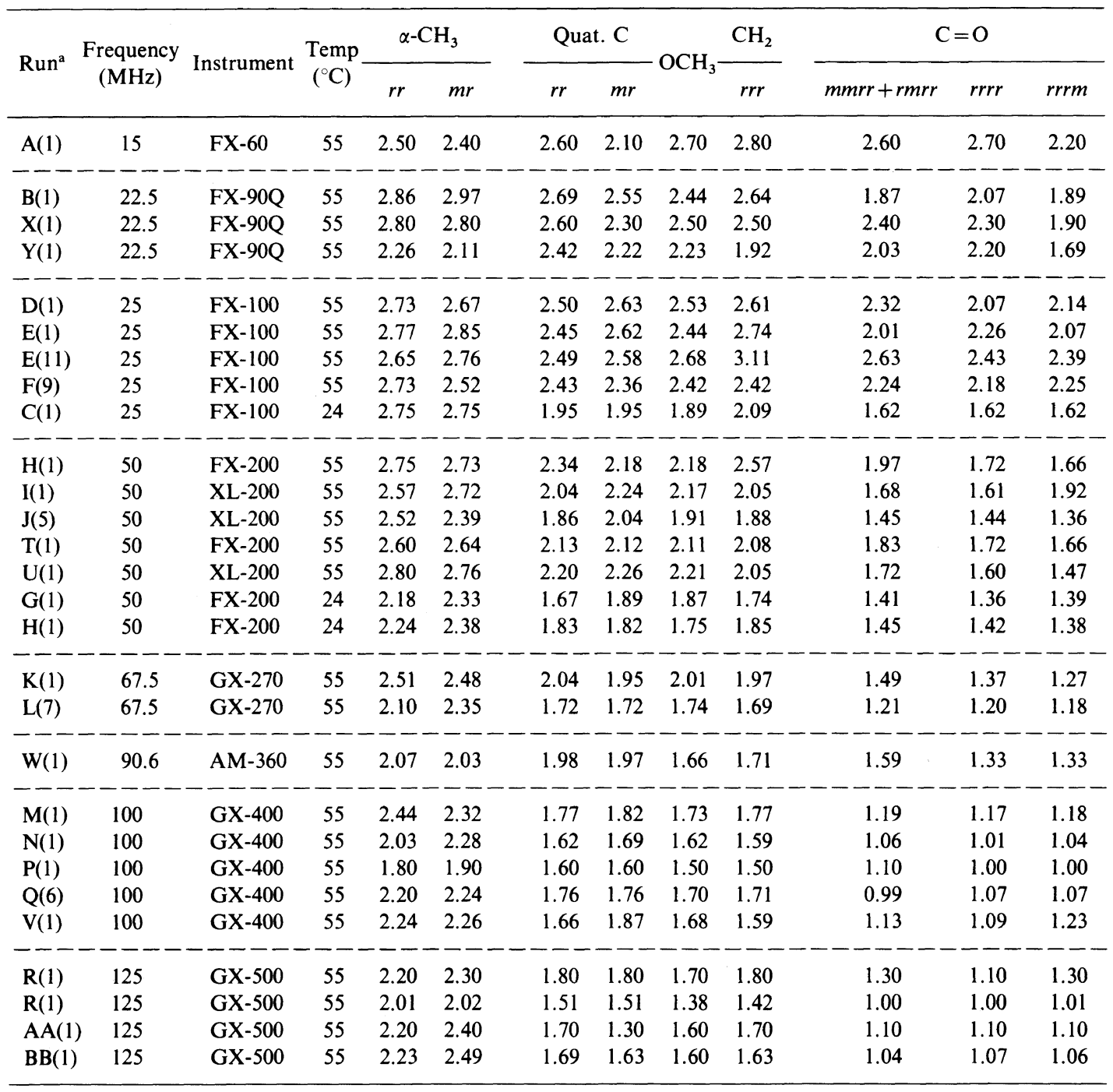

a Figures in parentheses denote sample numbers. 
R. CHûjô et al.

Table VIII. ${ }^{13} \mathrm{C}$ NOE of PMMA measured in $\mathrm{CDCl}_{3}$ at $55^{\circ} \mathrm{C}$ at different frequencies

\begin{tabular}{|c|c|c|c|c|c|c|c|c|c|c|}
\hline \multirow{2}{*}{$\begin{array}{c}\text { Frequency } \\
(\mathrm{MHz})\end{array}$} & \multirow{2}{*}{$n^{\mathrm{a}}$} & \multicolumn{2}{|c|}{$\alpha-\mathrm{CH}_{3}{ }^{\mathrm{b}}$} & \multicolumn{2}{|c|}{ Quat. $C^{b}$} & \multirow{2}{*}{$\mathrm{OCH}_{3}{ }^{\mathrm{b}}$} & \multirow{2}{*}{$\frac{\mathrm{CH}_{2}{ }^{\mathrm{b}}}{r r r}$} & \multicolumn{3}{|c|}{$\mathrm{C}=\mathrm{O}^{\mathrm{b}}$} \\
\hline & & $r r$ & $m r$ & $r r$ & $m r$ & & & $m m r r+r m r r$ & $r r r r$ & rrrm \\
\hline 15 & 1 & 2.80 & 2.40 & 2.60 & 2.10 & 2.70 & 2.80 & 2.60 & 2.70 & 2.22 \\
\hline \multirow[t]{2}{*}{22.5} & 3 & 2.64 & 2.63 & 2.57 & 2.36 & 2.39 & 2.35 & 2.10 & 2.19 & 1.83 \\
\hline & & $(10.2)$ & (14.3) & $(4.5)$ & ( 5.9$)$ & (4.8) & $(13.2)$ & $(10.5)$ & $(4.5)$ & ( 5.4) \\
\hline \multirow[t]{2}{*}{25} & 4 & 2.72 & 2.70 & 2.47 & 2.55 & 2.52 & 2.72 & 2.30 & 2.24 & 2.21 \\
\hline & & $(1.6)$ & ( 4.5$)$ & $(1.1)$ & ( 4.4) & (4.1) & $(9.2)$ & (9.8) & $(5.8)$ & ( 5.5$)$ \\
\hline $25^{\mathrm{c}}$ & 1 & 2.75 & 2.75 & 1.95 & 1.95 & 1.89 & 2.09 & 1.62 & 1.62 & 1.62 \\
\hline \multirow[t]{2}{*}{50} & 5 & 2.65 & 2.65 & 2.11 & 2.17 & 2.12 & 2.13 & 1.73 & 1.62 & 1.61 \\
\hline & & ( 4.1$)$ & ( 5.1) & (7.6) & ( 3.7$)$ & (5.1) & $(10.9)$ & ( 9.8$)$ & (6.6) & (11.7) \\
\hline \multirow[t]{2}{*}{$50^{c}$} & 2 & 2.21 & 2.36 & 1.75 & 1.86 & 1.80 & 1.80 & 1.43 & 1.39 & 1.39 \\
\hline & & ( 1.3$)$ & ( 1.2$)$ & (4.4) & ( 1.9$)$ & (3.1) & ( 3.1$)$ & ( 1.5$)$ & $(2.0)$ & (1.0) \\
\hline \multirow[t]{2}{*}{67.5} & 2 & 2.31 & 2.42 & 1.88 & 1.84 & 1.88 & 1.83 & 1.35 & 1.29 & 1.23 \\
\hline & & $(6.3)$ & ( 2.6) & $(8.3)$ & $(6.2)$ & (7.2) & $(7.7)$ & $(10.2)$ & $(6.6)$ & ( 3.5$)$ \\
\hline 90.6 & 1 & 2.07 & 2.03 & 1.98 & 1.97 & 1.66 & 1.71 & 1.59 & 1.33 & 1.33 \\
\hline \multirow[t]{2}{*}{100} & 5 & 2.14 & 2.20 & 1.68 & 1.75 & 1.63 & 1.63 & 1.09 & 1.07 & $1: 10$ \\
\hline & & $(10.0)$ & ( 6.9) & $(4.3)$ & $(5.6)$ & (4.9) & $(6.0)$ & ( 6.6) & (5.9) & ( 8.1$)$ \\
\hline \multirow[t]{2}{*}{125} & 4 & 2.16 & 2.30 & 1.68 & 1.56 & 1.57 & 1.63 & 1.11 & 1.07 & 1.12 \\
\hline & & $(4.0)$ & ( 7.7) & $(6.2)$ & $(11.7)$ & (7.5) & $(8.5)$ & (10.4) & (3.8) & (9.9) \\
\hline
\end{tabular}

a Number of determinations.

b Figures in parentheses represent precision (\%).

c Measurement was made at room temperature $\left(24^{\circ} \mathrm{C}\right)$.

thors excluded the data on the carbonyl carbon. ${ }^{18}$

Table VI summarizes the ${ }^{13} \mathrm{C}-T_{1}$ data obtained from the NMR samples prepared at several test sites by each collaborator. Similarly to the corresponding ${ }^{1} \mathrm{H}-T_{1}$ data, there is no substantial difference between the corresponding data in Tables IV and VI.

Longer $T_{1}$ 's in ${ }^{13} \mathrm{C}$ NMR at higher resonance frequencies may cause the great disadvantage of requiring longer delay time between rf pulses, resulting in decreased practical $\mathbf{S} / \mathrm{N}$ ratio obtainable in a limited period of time, because ${ }^{13} \mathrm{C}$ NMR measurement usually needs more iterative accumulation than ${ }^{1} \mathrm{H}$ NMR measurement.

\section{${ }^{13} \mathrm{C}$ Nuclear Overhauser Enhancement for PMMA}

${ }^{13} \mathrm{C}$ NOE directly affects the signal intensities in ${ }^{13} \mathrm{C}$ NMR spectrum so that the assessment of the NOE data and its precision is desired for quantitative analysis. The NOE can also afford information on segmental motion of polymer chains together with $T_{1}$ data. Here NOE is defined as follows:

$$
\mathrm{NOE}=I / I_{0}
$$

where $I$ and $I_{0}$ are observed signal intensities with and without proton irradiation. The theoretically expected maximum value for NOE is 2.988 if the ${ }^{13} \mathrm{C}$ nuclear megnetization relaxes through dipolar interaction with ${ }^{1} \mathrm{H}$ nucleus. $I_{0}$ was determined from the spectrum obtained under gated decoupling without NOE.

In Tables VII and VIII are summarized the individual data and mean values of NOE, respectively. Precision of NOE is as good as that of ${ }^{13} \mathrm{C}-T_{1}$. NOE's obtained at or below $25 \mathrm{MHz}$ are about $2.5-2.8$ and close to their theoretically expected maxima for all but carbonyl carbons. NOE values decrease with increasing magnetic field strength as seen in Figures 4 and 5. This is another disadvantage for measuring the spectrum of high $\mathrm{S} / \mathrm{N}$ ratios 


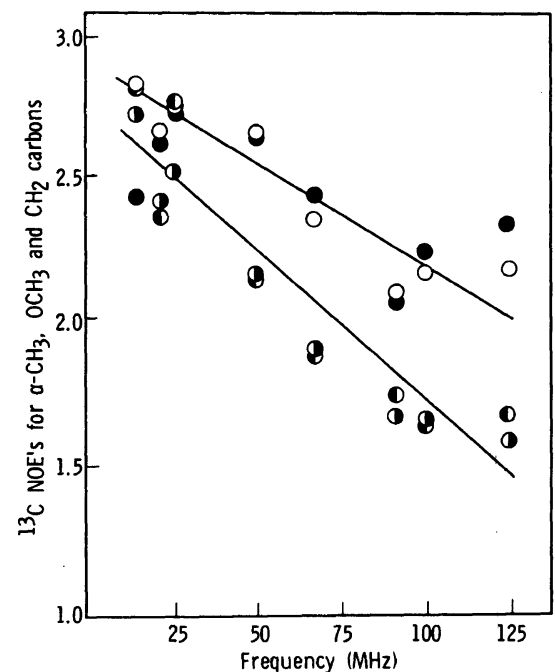

Figure 4. Frequency dependence of ${ }^{13} \mathrm{C}$ NOE's for $\alpha$ $\mathrm{CH}_{3}, \mathrm{OCH}_{3}$, and $\mathrm{CH}_{2}$ carbons of PMMA measured in $\mathrm{CDCl}_{3}$ at $55^{\circ} \mathrm{C}: \mathrm{O}, \alpha-\mathrm{CH}_{3}(r r) ; \bigcirc, \alpha-\mathrm{CH}_{3}(m r) ; \boldsymbol{O}, \mathrm{CH}_{2}$; (. $\mathrm{OCH}_{3}$.

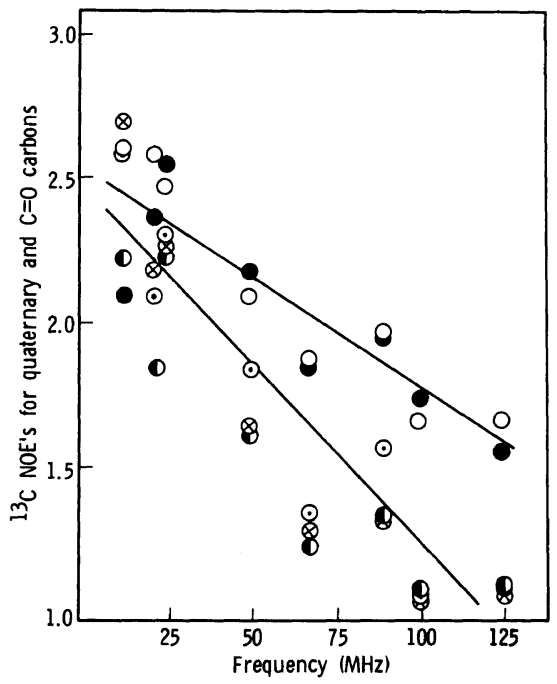

Figure 5. Frequency dependence of ${ }^{13} \mathrm{C}$ NOE's for quaternary and carbonyl carbons of PMMA measured in $\mathrm{CDCl}_{3}$ at $55^{\circ} \mathrm{C}$ : $\bigcirc$, quaternary $(r r)$; quaternary $(m r)$;, carbonyl $(r r m) ; \odot$, carbonyl $(m m r r+r m r r) ; \otimes$, carbonyl (rrrr).

Table IX. Relative intensities of ${ }^{13} \mathrm{C}$ NMR signals of PMMA in $\mathrm{CDCl}_{3}$ at $55^{\circ} \mathrm{C}^{\text {a }}$

\begin{tabular}{|c|c|c|c|c|c|c|c|c|c|c|c|c|}
\hline \multirow{2}{*}{$\begin{array}{c}\text { Frequency } \\
\mathrm{MHz}\end{array}$} & \multicolumn{4}{|c|}{ Complete decoupling ${ }^{\mathbf{b}}$} & \multicolumn{4}{|c|}{ Corrected by $\mathrm{NOE}^{\mathrm{b}}$} & \multicolumn{4}{|c|}{$\begin{array}{l}\text { Complete decoupling } \\
\text { without NOE }\end{array}$} \\
\hline & A & B & $\mathrm{C}$ & $n^{\mathrm{c}}$ & A & B & $\mathrm{C}$ & $n^{\mathrm{c}}$ & A & B & $\mathrm{C}$ & $n^{\mathfrak{c}}$ \\
\hline 22.5 & 0.86 & 1.93 & 1.00 & 3 & 1.11 & 2.15 & 1.07 & 3 & 1.12 & 2.21 & 1.19 & 2 \\
\hline 25 & 0.86 & 2.00 & 1.00 & 3 & 1.04 & 2.07 & 1.08 & 3 & 0.97 & 2.00 & 1.03 & 1 \\
\hline 50 & 0.54 & 1.45 & 0.92 & 3 & 0.87 & 1.80 & 1.14 & 3 & 0.89 & 2.00 & 1.03 & 1 \\
\hline 67.5 & 0.55 & 1.52 & 0.75 & 1 & 1.01 & 1.94 & 0.96 & 1 & 0.99 & 1.95 & 1.02 & 2 \\
\hline 90.6 & 0.43 & 1.33 & 0.70 & $1^{d}$ & 0.62 & 1.61 & 0.72 & $1^{d}$ & - & - & - & - \\
\hline 100 & 0.33 & 1.54 & 0.67 & $1^{d}$ & 0.66 & 2.05 & 0.84 & $\left.1^{\mathrm{d}}\right\}$ & & & & \\
\hline 100 & 0.46 & 1.33 & 0.69 & $1^{e}$ & 0.92 & 1.67 & 0.92 & $\left.1^{\mathrm{e}}\right\}$ & 1.00 & 2.06 & 1.08 & 2 \\
\hline 125 & 0.48 & 1.58 & 0.83 & $1^{\mathrm{e}}$ & 0.97 & 2.20 & 1.14 & $1^{\mathrm{e}}$ & 0.94 & 2.10 & 1.18 & 3 \\
\hline
\end{tabular}

a $\mathrm{A}=\mathrm{C}=\mathrm{O} / \alpha-\mathrm{CH}_{3}, \mathrm{~B}=\left(\mathrm{CH}_{2}+\mathrm{OCH}_{3}\right) / \alpha-\mathrm{CH}_{3}, \mathrm{C}=\mathrm{C}-4 / \alpha-\mathrm{CH}_{3}$.

b Data except for e were taken from the previous paper. ${ }^{1}$

c Number of determinations.

d,e Pulse repetition times were $c a$. $1 \mathrm{~s}$ and $10 \mathrm{~s}$, respectively.

by higher magnetic field instruments.

It is worth noting that the quaternary carbon, which has no directly attached hydrogens, shows similar NOE values to those for other carbons having directly attached hydrogens as $\mathrm{CH}_{2}$ and $\mathrm{CH}_{3}$ carbons. ${ }^{13} \mathrm{C}$ spinlattice relaxation of the quaternary carbon seems to be governed mainly by dipole-dipole interaction with its neighboring protons in methyl and methylene groups. The carbonyl carbon shows distinctively lower NOE values than other carbons and the value comes close to unity at higher observing frequencies of 100 and $125 \mathrm{MHz}$. Compared at each frequency, 
NOE for each carbon decreases in the order of $\alpha-\mathrm{CH}_{3}>$ quaternary carbon $\simeq \mathrm{OCH}_{3} \simeq \mathrm{CH}_{2}>$ carbonyl carbon. The differences between NOE values of these carbons increase with increasing resonance frequency as seen in Figures 4 and 5 , leading to inaccurate intensity ratios in completely decoupled spectra obtained at higher observing frequencies.

In the previous paper, ${ }^{1}$ intensity ratios in ${ }^{13} \mathrm{C}$ NMR signals of the PMMA measured at $90.6 \mathrm{MHz}$ and higher observing frequencies were reported to deviate from their theoretical values even after corrected by NOE values. The deviation was ascribed to the shorter repetition time of $\mathrm{rf}$ pulse (ca. $1 \mathrm{~s})$. The intensity measurements were repeated at 100 and $125 \mathrm{MHz}$ with a pulse repetition time of $10 \mathrm{~s}$ to avoid saturation of signals which would arise from longer ${ }^{13} \mathrm{C}-T_{1}$ at higher magnetic fields. The data obtained are shown in Table IX along with the previously reported data. Through correction by the NOE values, the intensity ratios measured at 100 and $125 \mathrm{MHz}$ with the repetition time of $10 \mathrm{~s}$ agreed well with the theoretically expected values. The average values of the intensity ratios determined from the spectra taken under the gated decoupling without NOE are also listed in the table and exhibit a good agreement with the theoretically expected values.

Acknowledgement. The authors are grateful to Mrs. F. Yano of Osaka University for her clerical assistance in preparing this manuscript.

\section{REFERENCES}

1. R. Chûjô, K. Hatada, R. Kitamaru, T Kitayama, H. Sato, and Y. Tanaka, Polym. J., 19, 413 (1987).

2. F. Horii, M. Nakagawa, R. Kitamaru, and members of NMR Research Group, SPSJ, Polym. Prepr., Jpn., 36, 3151 (1987).

3. K. Hatada, Y. Okamoto, K. Ohta, and H. Yuki, $J$. Polym. Sci., Polym. Lett. Ed., 14, 51 (1976).

4. K. Hatada, H. Ishikawa, T. Kitayama, and H. Yuki, Makromol. Chem., 178, 2753 (1977).

5. K. Hatada, T. Kitayama, Y. Okamoto, K. Ohta, Y. Umemura, and H. Yuki, Makromol. Chem., 179, 485 (1978).

6. F. Heatley and M. K. Cox, Polymer, 21, 381 (1980).

7. F. Heatley and M. K. Cox, Polymer, 22, 190 (1981)

8. J. Zajicek, H. Pivcová, and B. Schneider, Makromol. Chem., 182, 3169 (1981).

9. J. Zajicek, H. Pivcová, and B. Schneider, Makromol. Chem., 182, 3177 (1981).

10. J. R. Lyerla Jr., and T. T. Horikawa, J. Polym. Sci., Polym. Lett. Ed., 14, 641 (1976).

11. J. R. Lyerla, Jr., T. T. Horikawa, and D. E. Johnson, J. Am. Chem. Soc., 99, 2463 (1977).

12. Y. Inoue, T. Konno, R. Chûjô, and A. Nishioka, Makromol. Chem., 178, 2131 (1977).

13. Y. Inoue and T. Konno, Makromol. Chem., 179, 1311 (1978).

14. J. Spevácek and B. Schneider, Polymer, 19, 63 (1978).

15. G. C. Levy and D. Wang, Macromolecules, 19, 1013 (1986).

16. A. Abragam, "The Principles of Nuclear Magnetism," Oxford University Press, London and New York, 1961, Chapter 8.

17. G. C. Levy, J. P. Cargioli, and F. A. L. Anet, J. Am. Chem. Soc., 95, 1527 (1973).

18. G. C. Levy and D. Wang, Macromolecules, 19, 1013 (1986). 